University of Nebraska - Lincoln

DigitalCommons@University of Nebraska - Lincoln

Faculty Publications from the Harold W. Manter Laboratory of Parasitology

\title{
MICROEVOLUTION AND THE GENETIC STRUCTURE OF PARASITE POPULATIONS
}

Steven A. Nadler

University of California - Davis, sanadler@ucdavis.edu

Follow this and additional works at: https://digitalcommons.unl.edu/parasitologyfacpubs

Part of the Parasitology Commons

Nadler, Steven A., "MICROEVOLUTION AND THE GENETIC STRUCTURE OF PARASITE POPULATIONS" (1995). Faculty Publications from the Harold W. Manter Laboratory of Parasitology. 703.

https://digitalcommons.unl.edu/parasitologyfacpubs/703

This Article is brought to you for free and open access by the Parasitology, Harold W. Manter Laboratory of at DigitalCommons@University of Nebraska - Lincoln. It has been accepted for inclusion in Faculty Publications from the Harold W. Manter Laboratory of Parasitology by an authorized administrator of DigitalCommons@University of Nebraska - Lincoln. 


\title{
MICROEVOLUTION AND THE GENETIC STRUCTURE OF PARASITE POPULATIONS
}

\author{
Steven A. Nadler \\ Department of Biological Sciences, Northern Illinois University, DeKalb, Illinois 60115-2861
}

\begin{abstract}
The development of polymerase chain reaction-based methods for assessing the genotypes of small individual organisms will promote groundbreaking investigations of the genetic architecture of parasite populations. Both quantitative genetic models and general knowledge of parasite natural history are useful for making general predictions about the distribution of genetic variation over geographic space. However, designing experimental studies to assess relationships between specific life history variables and patterns of genetic structure in natural populations will be challenging. Traditional biochemical-genetic methods have already been used to study a limited number of parasite populations, and inferred patterns of genetic structure are distinctly different between certain species. Some of these differences in genetic architecture may be explained by parasite or host factors that either promote or retard the dissemination of life cycle stages over geographic space. Many additional empirical studies are needed to characterize basic features of parasite populations, including the spatial distribution and group size of random mating populations and levels of gene flow among parasite subpopulations.
\end{abstract}

Since the publication of On the Origin of Species (Darwin, 1859), the principal focus of studies in microevolution has been selection, although Darwin was aware that accident and interbreeding can oppose natural selection. Classical studies in ecological genetics, sensu Ford (1964), have documented and quantified the effects of natural selection on conspicuous phenotypic variation within populations. Subsequent studies of natural selection in wild populations of plants and animals (Endler, 1986) have proved invaluable for documenting additional examples and providing empirical evidence for theoretical predictions. Current studies in ecological genetics have, by necessity, become considerably more inclusive. This is because a thorough understanding of microevolution will occur only by considering, in an historical context, the effects of stochastic events, gene flow, natural selection, mutation, and mating systems on the metapopulation (the spatially separate, temporally extant, "interconnected" subpopulations of a species). Much of the theoretical groundwork for metapopulation studies was published prior to the advent of molecular genetic methods by the famous quantitative evolutionary geneticist Sewall Wright. It may be surprising to many parasitologists that Wright was a Master's student of Henry Baldwin Ward and published the first of his 211 scientific papers (Wright, 1912), on the morphology of the trematode Microphallus opacus! Wright's subsequent pioneering quantitative and theoretical studies in microevolution emphasized the importance of unpredictable changes in allelic frequencies due to stochastic events in finite populations (genetic drift), and modification of allele frequencies in populations due to the movement of gametes or individuals (gene flow). Wright's theoretical results have now received substantial empirical support from population-level studies of many free-living organisms. However, independent of any empirical corroboration, theoretical population genetic models are useful because of their predictive value regarding specific features of microevolution, such as the potentially complex interactions among demography, gene flow, genetic drift, natural selection, and other processes that influence genetic evolution.

Genetically based variation among individual parasites is a prerequisite for characterizing the genetic structure of their pop-

Received 21 November 1994; revised 2 February 1995; accepted 2 February 1995. ulations. Using molecular methods to assess the genotypes of individual parasites, although relatively labor intensive, is generally more straightforward than using the resulting data to infer microevolutionary pattern and process. Although significant progress has been made in developing the theory and practice of inferring microevolutionary patterns, e.g., intraspecific phylogeography (Avise et al., 1987), indirect quantification of gene flow (Wright, 1951; Slatkin, 1985, 1987; Weir, 1990), and coalescent theory (Hudson, 1990; Hudson et al., 1992), each of these inference methods is based on implicit or explicit assumptions that constitute the underlying models (Felsenstein, 1982). Interpretation of evolutionary process from the inferred pattern(s) adds another level of complexity because individual microevolutionary patterns may be compatible with multiple, nonexclusive processes. It must also be recognized that historical studies of micro- and macroevolutionary patterns are fundamentally different from investigations of processes that can be subjected to experimental manipulation. Finally, although historical studies may benefit from the sampling of additional genetic loci, nucleotide sites, or taxa, potentially intricate historical patterns may not be resolved in certain cases. Despite these limitations, microevolutionary studies have the potential to reveal basic information that is currently lacking on the population genetic structure of different parasite species, including parameters such as the average amount of gene flow among parasite "populations" contained within different individual hosts (each an infrapopulation, sensu Margolis et al. [1982]), and among metapopulations. Such studies are essential to understanding the probability for the dissemination of novel antihelminthic resistance mutations over geographic space and time.

Designing testable hypotheses concerning the relationship between genetic structure and specific ecological variables of parasites is likely to remain challenging. For free-living organisms, correlations between ecological variables and genetic structure often explain less than $50 \%$ of the overall variance (Avise, 1994). Obviously, the ecological genetics of parasites will be complicated not only by parasite-specific characteristics but also through their associations with hosts. For example, for most multicellular parasites, infrapopulations of definitive hosts are formed by recruitment (immigration) from the metapopulation and not as a result of natality within (or on) the host. Thus, both the vagility of the host and factors limiting infrapopulation density, 
for example, concomitant immunity, may serve to shape the genetic structure of recruited populations.

Although the paucity of available studies makes it premature to develop general conclusions about the genetic structure of parasite populations, it is likely that new technologies will soon promote groundbreaking research in this area. On the other hand, it is not premature to consider the types of questions that might be addressed in parasite population genetics. For example, what types of predictions about the genetic structure of parasite populations might result from examination of the basic features of microevolutionary theory? Given both specific evidence and untested doctrines on the population biology of parasites, what features of parasite natural history are likely to impact on their genetic structure? And finally, which, if any, of these predictions receives empirical support? These questions will be considered herein with a focus on multicellular parasites of animals.

\section{GENETIC DRIFT, GENE FLOW, AND MICROEVOLUTION}

Genetic drift is an important parameter influencing microevolution in populations of small size (Fisher, 1930; Wright, 1931). Wright demonstrated that it is the number of individuals contributing genes to the next generation $\left(N_{e}\right.$, or effective population size) and not the population census size that determines the relative amount of genetic drift in a deme (Wright, 1931). The smaller the $N_{e}$, the greater the likelihood that the allelic frequencies and genetic variability characteristic of a particular population will not be transmitted to the next generation. With small $N_{e}$, the heterozygosity of the population will be reduced due to an inbreeding effect, and random changes in allele frequencies will occur as a result of sampling variance (genetic drift). Under certain conditions, inbreeding and genetic drift may respond differentially to small $N_{e}$, which caused Kimura and Crow (1963) to distinguish between the inbreeding effective number and the variance effective number, respectively. For the variance effective number, it is the number of offspring that is critical to estimating sample variance or random genetic drift. For the inbreeding effective number it is the quantity of reproducing individuals in the parental generation that determines the likelihood of identity by descent (autozygosity) for alleles at a locus. In many instances, these different approaches to calculating effective number will yield similar results; however, this illustrates just one of many potential difficulties of estimating the effective size, which is particularly complex for species with highly subdivided populations (Chesser et al., 1993). In addition, models for estimating $N_{e}$ are not designed to incorporate the complications introduced by organisms with elaborate life cycles, for example, the clonal (agametic) reproductive strategies of larval digeneans (Esch and Fernández, 1993).

One estimator of effective population size that employs several simplifying assumptions (Wright, 1931, 1938) can be calculated from the formula $N_{\mathrm{e}}=4 N_{m} N_{f} / N_{m}+N_{f}$ where $N_{m}$ and $N_{f}$ are the number of males and females, respectively, that serve as parents in a particular generation. This formula is based, in part, on assumptions of random mating and the possibility of self-fertilization. The calculated $N_{e}$ applies to a single generation; however, if $N_{e}$ is variable over time, generations with smaller $N_{e}$ will have the greatest influence on the average $N_{e}$ over many generations. This is reflected by the observation that multiple-generation $N_{e}$ ("long-term" $N_{e}$ ) can be estimated by calculating the harmonic mean of $N_{e}$ for individual generations (Crow and Kimura, 1970). Effective population size will also be reduced substantially in comparison to the total number of breeding adults by a skewed sex ratio because with biparental reproduction, half of the alleles in offspring must come from each sex. For example, a parasite infrapopulation consisting of 1 male and 12 reproducing females (a possibility for certain nematodes) has an $N_{e}$ of only 3.7 by Wright's (1931) formula. Structured populations with an $N_{e}$ of approximately 200 are likely to experience moderate amounts of genetic differentiation due to drift, whereas demes $\geq 1,000$ will be only marginally affected, assuming average rates of mutation (Wright, 1978; Falconer, 1981). Microevolution in populations of $N_{e}<10$ will be characterized by nonadaptive differentiation because stochastic changes will overcome natural selection, regardless of intensity (Wright, 1978; Shields, 1993). Mean individual heterozygosity will also decrease at a relatively rapid rate when $N_{e}$ $<1,000$ because average per generation mutation rates per locus are insufficient to replace variation lost by random genetic drift. Low long-term $N_{e}$ or extreme population size bottlenecks may account for abnormally low levels of heterozygosity in certain helminth populations (Bullini et al., 1986; Nadler, 1990; Esch and Fernández, 1993). However, both the nature of recruitment of individuals comprising infrapopulations within definitive hosts and the potential longevity of certain other parasite infrapopulations within the environment, e.g., long-lived eggs or larvae within paratenic hosts, may complicate the interpretation of infrapopulation $N_{e}$ on metapopulation genetic diversity. Wright (1940) noted that in species where local populations are subject to frequent extinction with repopulation from a few immigrants, $N_{e}$ will be drastically reduced despite the large number of individuals that may comprise the suprapopulation. Maruyama and Kimura (1980) developed a model for estimating $N_{e}$ based on estimates of the subpopulation extinction rate, migration rate between subpopulations, and mutation rate to neutral alleles. Although such estimates are not currently available for parasites, theoretical models (Maruyama and Kimura, 1980) have shown that if the rate of subpopulation extinction is much higher than the migration rate of individuals between subpopulations, the $N_{e}$ of the suprapopulation (sensu Margolis et al., 1982) will be markedly reduced and genetic divergence of subpopulations is prevented.

To illustrate the possible impact of genetic drift on microevolution within a small deme of diploid parasites it is instructive to consider the probability of fixation (frequency of 1.0) for an allele, and the average time required to fixation for those alleles that are eventually fixed. The following examples are included to show that a simple deterministic model of allele frequency change, in which the allele of greatest fitness eventually replaces others, is not an appropriate model of microevolution for small natural populations of parasitic organisms. The variables related to estimating the probability of fixation for a particular allele include the $N_{e}$ of the deme, the frequency of the allele, and whether the allele is selectively neutral, advantageous, or deleterious. Because of the influence of genetic drift at all loci irrespective of the relative fitness of alternative alleles, fixation of an allele is a probabilistic process (Kimura, 1962). For example, under an additive model of selection (het- 
erozygote with mean fitness of the 2 homozygous genotypes), the probability of fixation $(P)$ for an advantageous allele introduced by mutation is, $P=1-e^{-2 N s p} / 1-e^{-2 N s}$, where $s$ is the selection coefficient and $p$ is the frequency of the advantageous allele (Hedrick, 1983). For a neutral allele, the probability of fixation is a function of its frequency; thus, for a neutral mutation, $P=1 / 2 N$. In a population where $N=N_{e}=500$, the respective probabilities of fixation for an allele that is slightly advantageous $(s=0.01)$, markedly advantageous $(s=0.10)$, or neutral, are $P \approx 0.009,0.095$, and 0.001 , respectively. For a population where $N=N_{e}=50$, the respective probabilities of fixation for the same selection values are $P \approx 0.016,0.095$, and 0.010 . In both populations, there is a high probability $(\approx 90 \%)$ that a markedly advantageous allele introduced by mutation as a single copy will be lost by random genetic drift. Note also that the neutral and nearly neutral mutations have significantly greater probabilities of fixation in the smaller population (10-fold greater for the neutral mutation) due to genetic drift. Although counterintuitive, a slightly deleterious mutation also has a slight chance of being fixed in small natural populations. Most alleles introduced by mutation have a high probability of loss within large populations, and stochastic effects are responsible for the higher likelihood of fixation within very small populations.

The interaction of natural selection with random genetic drift in the microevolution of small populations can be illustrated by the average time required to reach fixation $(t)$ for an allele destined to reach a frequency of 1 . For a selectively neutral allele introduced by mutation, the average conditional fixation time $(t) \approx 4 N$ generations (Kimura and Ohta, 1969). For a parasite population with $N \approx N_{e}=1,000$ and a generation time of 90 days, a neutral mutation will require approximately $1,000 \mathrm{yr}$ for fixation; however, when $N=50, t \approx 50 \mathrm{yr}$. Time to fixation for a selectively advantageous allele is expressed by the formula $t \approx(2 / s) \ln (2 N)$ generations (Maruyama and Kimura, 1974). Considering an advantageous mutation $(s=0.1)$ that is destined to reach fixation (about $9.5 \%$ of such mutations when $N_{e}=50$ ), $t \approx 37 \mathrm{yr}$ for $N=1,000$, and $t \approx 23 \mathrm{yr}$ for $N=50$. This difference in the rate of fixation between selectively neutral versus nonneutral mutations demonstrates that selection can be particularly effective in rapidly changing the genetic composition of populations of small $N_{e}$. The results of this example are also consistent with expectations of neutral-mutation theory (Kimura, 1983), because it reveals that neutral mutations tend to have longer "transit" times within natural populations.

How will the genetic structure and evolution of parasite populations be shaped by the movement of parasite gametes, individuals, or groups of individuals among demes? Different perspectives concerning the evolutionary process have yielded contrasting viewpoints about the role of gene flow in evolution. The traditional viewpoint is that gene flow represents a constraining evolutionary force that, if sufficiently high, prevents marked genetic differentiation among subpopulations. From this same perspective, absence of gene flow is a prerequisite for classical allopatric speciation. In contrast, Wright $(1932,1982)$ and other population geneticists have developed models that show that gene flow may serve as a creative force in the evolution of populations. This viewpoint has been adopted by Mayr (1954) in developing the peripatric model of speciation. A key question is how much gene flow is necessary to prevent the genetic differentiation of subpopulations? The answer depends on the na- ture of the variation under consideration. With selective neutrality, much less gene flow is required to prevent substantial genetic differentiation than for cases where one allele is of selective advantage in one subpopulation and a different allele is favored in another subpopulation.

The amount of gene flow among subpopulations in combination with other population parameters determines if evolution proceeds independently in different demes. In general, with very high levels of gene flow among demes, different subpopulations will evolve as a single evolutionary unit; with low levels of gene flow among demes, different subpopulations may evolve independently. Theoretical models are informative concerning how loci with neutral versus non-neutral variation respond to differing levels of gene flow. Wright's island model of population structure, in which each subpopulation has a fraction $m$ of its residents replaced with individuals selected at random from the other subpopulations or islands, is instructive for the behavior of neutral or nearly neutral loci. If the quantity $\mathrm{Nm}$ (where $\mathrm{N}$ $=$ the effective population size) is $>1$, gene flow will overcome random genetic drift and prevent local differentiation at equilibrium. In many cases only a small amount of gene flow per generation, for example the successful reproduction of a single immigrant, is required to prevent genetic differentiation between 2 subpopulations. Conversely, if $N m<1$, genetic drift will act independently in the subpopulations to determine the allelic frequencies for "nearly neutral" loci (Slatkin, 1987). The amount of time required to reach genetic equilibrium for the subpopulations is dependent on the effective population size and the immigration rate (Takahata, 1983) and may be a large number of generations. This situation is predictably different in cases where $N_{e}$ is moderate to large and the locus includes alleles that are strongly affected by selection (Haldane, 1930; Nagylaki, 1975). Even in the presence of relatively high levels of gene flow introducing a less favorable allele into a subpopulation, natural selection will tend to maintain a high frequency of the advantageous allele. Unlike the case for neutral loci, genetic equilibrium will tend to be established quickly under most rates of immigration, the amount of time depending on the relative fitness of the 2 alleles. Thus, moderate-to-high levels of gene flow may be relatively unimportant in preventing local differentiation when there is strong differential selection in different subpopulations.

Sewall Wright was instrumental in modeling how gene flow may serve as a creative, rather than a constraining force in the evolution of small populations, and his shifting-balance (Wright, 1932) and interdemic selection (Wright, 1956) models of microevolution both have relevance to certain parasitic organisms. In both cases, microevolutionary change is facilitated by small effective population size and genetic drift. In the shifting-balance model, the relative fitness of subpopulations may be visualized in terms of a 3-dimensional landscape. A local population may ascend the available adaptive surface and achieve a local optimal fitness, but remain isolated (by valleys of lower fitness) from adjacent peaks representing combinations of genes of greater relative fitness. With small $N_{e}$ and low migration rates, random genetic drift may overcome selection and fix genes or groups of genes that constitute a peak of greater fitness, and gene flow could then spread this more fit genotype. The conditions that are conducive for this scenario are also likely to cause deme extinction in demographically stable species prior to gene flow 
and spread of the more fit genotype. However, for certain parasites and other species possessing a "weedy" population structure, colonization of new resource patches (hosts) is in itself a type of gene flow (Slatkin, 1987) that may counterbalance the local extirpation often associated with the demographic instability of metapopulations. Gene flow via local population extinction and recolonization of new hosts can be more effective in spreading new parasite genotypes than gene flow between resident metapopulations (Slatkin, 1987). Interdemic (group) selection should favor the evolution of traits that enhance dispersal ability, which for parasites is likely to include the utilization of paratenic (transfer) hosts, vagile intermediate hosts, or vectors for transmission.

\section{CHARACTERIZING GENE FLOW AND GENETIC STRUCTURE}

Many recent studies have focused on the genetic variability of parasites, e.g., protein polymorphism and mean individual heterozygosity, in relation to natural selection from the panselectionist viewpoint, or to facets of population structure from a neutralist viewpoint (for review, see Nadler, 1990; Esch and Fernández, 1993). Some of these studies have included data on allelic frequencies from samples representing different geographic localities; however, observed frequency differences alone cannot be used to characterize amounts of gene flow among populations directly. Instead, indirect methods of estimating levels of gene flow from patterns of allelic frequency distributions are needed to distinguish among differences resulting from gene flow, genetic drift, and natural selection. At least 3 different general approaches have been used to estimate levels of gene flow from either allozyme allelic frequency or nucleotide sequence data. Traditionally, $F$-statistics as developed by Wright (1951) or modified by others (Weir and Cockerham, 1984) are used to quantify inbreeding due to population subdivision $\left(F_{S T}\right)$, and this measure is applied to a model for estimating the parameters $\mathrm{Nm}$, where $m$ is the proportion of alleles of migrant origin in a deme and $N$ is the local population size. Other approaches for estimating $\mathrm{Nm}$ include methods based on the distribution of rare or unique alleles among subpopulations (Slatkin, 1985; Barton and Slatkin, 1986), or in the case of nucleotide sequence data, the nodes and branch lengths of a gene tree for a nonrecombining DNA region (Slatkin and Maddison, 1989; Hudson et al., 1992).

In addition to their application for estimating gene flow, $F$-statistics can be used to quantify levels of inbreeding with respect to different reference populations (Wright, 1922, 1965). Wright developed a numerical method to analyze systems of mating (ancestor-offspring relationships in pedigrees), such that a single numerical quantity $(F)$ is sufficient to summarize the correlation of genetic state at a locus. $F$ represents the correlation between uniting gametes such that under random mating $F=0$, and with sustained inbreeding beyond that expected given the effective population size, $F$ will be a positive number $\leq 1$. One effect of inbreeding is to reduce the individual heterozygosity within populations. The inbreeding coefficient $\left(F_{I S}\right)$ describes the reduction in heterozygosity of an individual within its subpopulation compared to that expected in a randomly mating population with the same allelic frequencies. Inbreeding coefficients are calculated by determining the genotypes of individual or- ganisms representing a population sample, and comparing the proportion of heterozygous genotypes observed $(H)$ to those expected in a randomly mating population $\left(H_{0}\right.$, or $2 p q$ in the Hardy-Weinberg formula), where $F=\left(H_{0}-H\right) / H_{0}$. The inbreeding coefficient may be interpreted as the probability that 2 alleles in a diploid individual are autozygous or identical by descent, that is, share common ancestry via replication from a single ancestral allele. Note that 2 alleles possessed by an individual can be identical in nucleotide sequence yet different with respect to replication or immediate common ancestry (the allozygous condition). The concept of inbreeding may be extended beyond a single subpopulation to estimate the probability of identity by descent for alleles selected at random from a sample representing more than 1 subpopulation. Subdivided populations may be characterized by nonrandom mating, and this type of inbreeding can be quantified at 2 additional levels, the subpopulation relative to the total population $\left(F_{S T}\right)$, and the individual with respect to the total population $\left(F_{I T}\right) . F_{S T}$ measures the reduction in heterozygosity of a subpopulation due to random genetic drift; the overall inbreeding coefficient $\left(F_{I T}\right)$ reflects the reduction in heterozygosity due to nonrandom mating within subpopulations $\left(F_{I S}\right)$ plus that due to population subdivision $\left(F_{S T}\right)$. The interrelationship among these 3 inbreeding coefficients is $\left(1-F_{I T}\right)=\left(1-F_{I S}\right)\left(1-F_{S T}\right)$. Calculations of $F$-statistics from allelic frequency data should be corrected for biases that may be introduced by sampling few individuals per subpopulation (Van Den Bussche et al., 1986), which is likely to be the case in many studies of natural parasite infrapopulations. The variances of $F$-statistics across loci (Nei and Chakravarti, 1977; Weir and Cockerham, 1984) are frequently significant and commonly unreported, therefore; small differences between mean $F$-statistics in empirical studies should be interpreted cautiously.

$F$-statistics calculated from genetic data are frequently used to estimate levels of gene flow among demes indirectly. Estimates of host gene flow, although of interest for comparative purposes, are unlikely to be informative about the range of possible gene flow levels for their parasites, with the possible exception of parasites that are either exclusively sexually transmitted or contact-transmitted at the time of host reproduction. Obviously, traditional direct estimates of gene flow, e.g., markrecapture methods, are not appropriate for adult parasites that do not disperse to new hosts. By contrast, the direct approach of tracking the movement of unique genetic markers has been used to study gene flow over geographic space in ecological time (Handel, 1982), and this could be applied to parasitic organisms. However, one disadvantage of all direct approaches is the limited timescale of study because evolutionarily important yet sporadic increases in gene flow are likely to be missed by direct measurements. For parasites, episodes of high gene flow may be triggered by certain rare abiotic or biotic factors, including the establishment of novel parasite populations through the introduction of new definitive hosts to an ecosystem (Kennedy and Burrough, 1977; Kennedy, 1987)

Indirect estimates of gene flow are usually based on the current geographic distribution of allele frequencies. The advantage of indirect measurements is that they provide information on the average amount of gene flow over long spans of time (Slatkin, 1987). However, indirect measures depend, in part, on explicit assumptions of a specified model of inference to estimate how 
TABLE I. Examples of ecological and natural history factors that may influence the population genetic structure of animal parasites. These predictions are of heuristic value, but may be confounded in certain taxa due to the influences of other interrelated variables.

\begin{tabular}{|c|c|}
\hline $\begin{array}{l}\text { Factors increasing } \\
\text { genetic structure }\end{array}$ & $\begin{array}{l}\text { Factors reducing } \\
\text { genetic structure }\end{array}$ \\
\hline $\begin{array}{l}\text { Sedentary definitive host or ex- } \\
\text { treme morbidity of all infected } \\
\text { hosts }\end{array}$ & $\begin{array}{l}\text { Highly vagile hosts (definitive, } \\
\text { intermediate, paratenic) or vec- } \\
\text { tors }\end{array}$ \\
\hline $\begin{array}{l}\text { Life cycle includes a large num- } \\
\text { ber of specific obligate hosts }\end{array}$ & $\begin{array}{l}\text { Persistent (long-lived) life cycle } \\
\text { stages in environment or defin- } \\
\text { itive host }\end{array}$ \\
\hline $\begin{array}{l}\text { Suitable parasite niches patchily } \\
\text { distributed in space or time }\end{array}$ & $\begin{array}{l}\text { Low definitive host specificity/ } \\
\text { many reservoir hosts }\end{array}$ \\
\hline $\begin{array}{l}\text { Small effective size for parasite } \\
\text { population }\end{array}$ & $\begin{array}{l}\text { Underdispersed distribution of } \\
\text { parasites among hosts }\end{array}$ \\
\hline $\begin{array}{l}\text { Parasite predominantly self-fer- } \\
\text { tilizing }\end{array}$ & $\begin{array}{l}\text { Life history with frequent meta- } \\
\text { population extinction followed }\end{array}$ \\
\hline $\begin{array}{l}\text { Physical contact between defini- } \\
\text { tive hosts required for trans- } \\
\text { mission }\end{array}$ & by reestablishment \\
\hline
\end{tabular}

much gene flow must have occurred to explain the observed geographic pattern of allele frequencies. For example, with respect to migration, Wright's island model for estimating gene flow assumes that all subpopulations are equally accessible to each other. For natural populations, this is equivalent to the assumption of extremely high dispersal ability for migrants. By contrast, a "stepping-stone" model of population structure (Slatkin and Barton, 1989) restricts migration to neighboring subpopulations and considers the geographic distance between subpopulations.

One assumption of all indirect methods is that the subpopulations have reached genetic equilibrium. Theoretical studies demonstrate that the time required for the fixation index $\left(F_{S T}\right)$ to reach equilibrium can be very long in populations of large size. Given an island model, $F_{S T}$ will reach an equilibrium depending on either effective population size or $1 / m$ (where $m=$ migration rate to subpopulations), depending on the time scale that is smaller (Takahata, 1983; Crow and Aoki, 1984). In systems with a relatively high migration rate, e.g., $m>0.01, F_{S T}$ will approach equilibrium in less than 100 generations. For stepping-stone models of gene flow, which would seem to be more appropriate for some parasitic organisms, time to equilibrium for $F_{S T}$ is even greater than for island models (Slatkin, 1993). However, patterns of $F_{S T}$ prior to the establishment of genetic equilibrium can also be informative, particularly for organisms such as parasites in which rapid colonization of previously uninfected hosts is followed by gene flow between adjacent infrapopulations or metapopulations (Slatkin, 1993). By focusing on pairwise comparisons of such subpopulations to estimate $N m$ from $F_{S T}$, a parameter denoted $M$ may be calculated (Slatkin, 1991, 1993). This parameter is dependent on the geographic distance between pairs of locations in both 1- and 2-dimensional stepping-stone models of gene flow. Slatkin (1993) found that the isolation-by-distance pattern spreads over time such that there is a relationship between $M$ and geographic distance only for a discrete geographic range, the size of which is dependent upon time since colonization. Thus, this model relates isolation-by-distance to time since colonization and does not depend on the restrictive assumption of genetic equilibrium.

\section{BIOLOGICAL INSIGHTS AND EMPIRICAL EVIDENCE}

From the preceding discussion it should be clear that the models underlying methods of inference in population genetics entail certain assumptions that may compromise the interpretation of data. However, the major current limitation for understanding helminth population genetic structure is the lack of available data. No doubt, this is primarily the result of technical limitations associated with obtaining biochemical-genetic data from small individual organisms. Approaches using the polymerase chain reaction (PCR) or other sensitive molecular methods (reviewed in Hillis and Moritz, 1990; Avise, 1994; Grant, 1994) offer new possibilities for studying numerous genetic loci from individual parasites at the DNA-level; however, these approaches have yet to be utilized fully.

Many basic population parameters remain to be defined for parasite species. For example, what group of individuals represents the deme or random mating population, and how does the corresponding neighborhood area and size differ among taxa? Although the infrapopulation represents the immediate group of interbreeding individuals, the genetic composition of this group may change by recruitment during the life span of the host. In addition, it seems likely that for certain parasites, individual hosts will differ dramatically in their histories of recruitment, and this may produce a chaotic pattern of parasite genetic structure among hosts. For parasites with geographically wide-ranging hosts, infrapopulations may be less inbred than if mating occurred at random among parasites within the metapopulation. By contrast, for a parasite species that may continually complete its life cycle within (or on) a single individual host, infrapopulations should primarily represent descendants of the colonizers, and such populations are likely to be highly inbred. For certain other heteroxenous species such as human schistosomes, premunition may have a similar effect, that is, restriction of the genetic composition of the deme to the colonizers.

The genetic structure of parasite populations will be shaped strongly by ecological factors of individual species, including their demography, life cycle, mechanisms of dispersal, and host specificity (Table I). Characteristics of species such as the mating system and population-level attributes such as the effective size will affect certain aspects of demes, including the likelihood of random genetic drift. For example, self-fertilization is a form of restricted genetic recombination that may result in local genetic differentiation in certain cestode species (Lymbery and Thompson, 1988). Likewise, haplodiploid reproduction among pinworms in combination with other life history features of the Oxyurida may promote extensive inbreeding within hosts (Adamson, 1989). Perhaps more often than for free-living organisms, parasite species may experience considerable variation in the parameters influencing genetic structure due to variation in ecological factors among different definitive host species (in generalist parasites) or due to differences among parasite communities. Thus, special caution is advisable for studies of parasites because no single investigation is likely to be representative of conditions for populations of the entire species. 
Price (1980) argued that from the parasite's "point of view," resources, i.e., parasite-host niche overlap, will have a patchy distribution in both space and time, and that host-parasite systems will experience considerable disruption due to their complexity, low probability of colonization, and high probability of extinction. Increased complexity of biotic associations, for example the number of obligate hosts in the life cycle of a parasite, should increase resource patchiness (Price, 1980). This is supported by theoretical models in which increasing the complexity of parasite systems decreases their stability (May, 1973). Price (1980) also characterized the "within-patch" population dynamics of parasites as a nonequilibrium system. This viewpoint is also consistent with limited evidence suggesting that numerous density-independent factors may regulate the infrapopulation size of certain species (Esch and Fernández, 1993). Many other factors may also contribute to resource patchiness, for example variation in genetic predisposition to infection among individual hosts, which can influence patterns of parasite aggregation (Schad and Anderson, 1985).

Although different levels of resource patchiness should have predictable effects on the genetic structure of parasite populations, assessing individual ecological factors promoting patchiness is likely to be difficult due to the large number of interactions in host-parasite systems and potential correlations among life history traits of parasites. In addition, although the demographic structure of parasites as assessed by censusing adult infrapopulations in definitive hosts may be unstable (Price, 1980; Esch and Fernández, 1993), the gene pool of parasite metapopulations may have greater stability for cases in which species produce large numbers of life cycle stages that persist in the environment for periods that exceed several parasite generations. This situation is analogous to the influence of seed dormancy and the seed pool on the evolution of plant populations. For many parasite species, colonization of uninfected definitive hosts is not analogous to a simple island model, with dispersal from adjacent colonized hosts. Clearly, long-lived life cycle stages are not produced by all helminths, and such differences may prove useful for predicting variation in population genetic architecture. For example, experimental human infections with Ascaris lumbricoides have demonstrated that ascaridoid eggs may remain infective for $10 \mathrm{yr}$ or more in soil (Brudastov et al., 1971); in contrast, Enterobius spp. infecting humans are characterized by eggs that remain viable for approximately 1 wk. Thus, the life history pattern of human pinworms is more likely to promote genetic structuring among populations.

Given the range of ecological diversity that is characteristic of parasites, a broad spectrum of genetic architectures is likely to be revealed as more empirical studies are undertaken. Published studies have already revealed variation in genetic structure among different species and, as in free-living organisms (Avise, 1994), species with life histories conducive to the geographic movement of individuals or dissemination of life cycle stages tend to show less population structure than those with lower vagility. For example, Paggi et al. (1991) and Nascetti et al. (1993) have used multilocus protein-electrophoretic data to show that species of ascaridoid nematodes using seal definitive hosts (and fish/invertebrate intermediate and paratenic hosts) have low amounts of genetic structuring across broad geographic ranges of the Arctic-Atlantic Boreal region. Geographic population samples of the species referred to as Contracaecum os- culatum "A" (7 localities) and C. osculatum "B" (19 localities) had average $F_{S T}$ values of 0.042 and 0.046 , respectively, over distances spanning more than 5,000 km (Nascetti et al., 1993). Likewise, 3 species in the Pseudoterranova decipiens complex (referred to as "A, B, and C" by the authors), which tend to share the same definitive hosts as the $C$. osculatum species, showed average $F_{S T}$ values of $0.059,0.055$, and 0.021 , respectively, for the cryptic species "A," "B," and "C" (Paggi et al., 1991). These studies are particularly noteworthy in that species in these 2 complexes are known to have the same general life cycle patterns, and would seem to share many of the same intermediate, paratenic, and definitive hosts. The distribution of $94-98 \%$ of the total estimated gene diversity within all geographic localities is consistent with the hypothesis of Nascetti et al. (1993) that migration of the definitive hosts (seals) in combination with the transport of larvae in fish and invertebrates (intermediate/paratenic hosts) serve as highly effective mechanisms of gene flow over large geographic distances. Interestingly, studies of population structure in marine fishes also show high gene flow, with more than $98 \%$ of the total gene diversity found within all localities (Gyllensten, 1985).

Several other studies have suggested a relationship between high parasite dispersion or host vagility and low genetic structure for parasite populations. McManus (1985) reported on a helminth system that would appear to have the potential for high gene flow among localities. Ligula intestinalis, a pseudophyllidean from fish-eating birds, has an extremely wide intermediate host range ( $>20$ cyprinid fish species may host plerocercoids). This life history would appear to be conducive to high gene flow due to properties intrinsic to both hosts and parasite. First, as a consequence of their high vagility, birds are characterized by the lowest levels of average population structure among vertebrates (Ward et al., 1992); this host property should serve to disperse parasite eggs effectively. Second, this parasite can use many different fish intermediate hosts, which means that many aquatic communities should be effective sources of infection. Although only 1 polymorphic enzyme locus was assessed among population samples of plerocercoids obtained from fish, samples (with $n>15$ ) from 4 geographic localities in southern England showed very similar frequencies for the 2 alleles at the phosphoglucomutase- 2 locus, suggesting that avian definitive hosts may be responsible for high levels of gene flow via egg dispersal among localities. Similarly, the potential role of low host specificity and high host mobility for reducing genetic structure was shown by Hilburn and Sattler (1986a) in an electrophoretic study of the lone star tick, Amblyomma americanum. Analysis of 9 geographic population samples distributed across the widespread range of this species yielded an average $F_{S T}$ value of 0.037 , and no evidence for an isolation-by-distance effect. Because life cycle stages of this 3-host tick are relatively sedentary off the host, Hilburn and Sattler (1986a, 1986b) inferred that the observed lack of genetic structure must result from host mobility. Amblyomma americanum fits several of the general predictions for reduced genetic structure in Table I, including high vagility hosts (including deer and cattle), low host specificity, and the potential for a long life span for individual parasites.

Most recently, studies of mitochondrial-DNA (mtDNA) phylogeography in Ostertagia ostertagi (Blouin et al., 1992; Dame et al., 1993) have revealed very high genetic diversity within 
geographic populations, but extremely low differentiation among localities. Using an estimate of mitochondrial genetic diversity that is analogous to $F_{S T}$, Bouin et al. (1992) reported that, on average, less than $1 \%$ of the total gene diversity was partitioned between geographic populations. For $O$. ostertagi, gene flow among localities appears to be high, and may be mediated by the transport of cattle throughout the U.S.A. Interestingly, despite this lack of observed differentiation in mtDNA (and with the inference of high levels of gene flow), genetically based geographic differences in the timing of developmental arrest (hypobiosis) have been demonstrated for temperate and subtropical populations of $O$. ostertagi (Smeal and Donald, 1981; Frank et al., 1986, 1988). Thus, Blouin et al. (1992) have hypothesized that the variation in timing of hypobiosis between the northern and southern U.S. populations may be maintained by strong selection in the presence of high gene flow, and that high intrapopulation diversity is a product of the large effective size of the populations (4-8 million individuals per geographic population based on the observed diversity of mtDNA).

Only a few published studies are available to demonstrate the potential effects of natural history traits that are expected to increase the genetic structure of parasite populations. Among studied parasites, pocket gopher chewing lice have shown levels of population genetic subdivision that are among the highest reported over limited geographic scales for any animal. For example, the mean $F_{S T}$ value for microgeographic (within-locality) differentiation of Geomydoecus actuosi infrapopulations ( 5 independent comparisons) was 0.092 , and ranged from 0.039 to 0.162 (Nadler et al., 1990). Macrogeographic differentiation of these infrapopulations over the $200-\mathrm{km}$ range of the study area revealed an average $F_{S T}$ of 0.24 , which was virtually identical to that inferred for their hosts in a previous study (Hafner et al., 1983). The natural history of the pocket gopher-chewing louse assemblage would seem to include many factors promoting population subdivision. For example, the lice are autoxenous and exclusively contact-transmitted, pocket gophers are fossorial and actively avoid intraspecific contact, and louse populations appear to suffer seasonal bottlenecks in size that should reduce $N_{e}$ (Nadler et al., 1990). Thus, gene flow among louse infrapopulations is dependent upon interhost contact, which in pocket gophers is primarily limited to mating encounters and the rearing of young. This unusual linkage between pocket gopher reproduction and louse transfer means that host gene flow is likely to represent the upper boundary for louse gene flow in this assemblage.

Recent research on Ascaris suum (Nadler et al., 1995), using protein electrophoretic and RAPD PCR-based markers, has also revealed significant patterns of genetic structure, with reported values of average $F_{S T}$ for infrapopulations and localities indicative of moderate genetic differentiation. For example, values of $F_{S T}$ among 7 infrapopulations were approximately 0.09 as inferred from both isoenzyme and RAPD markers. When infrapopulations from each collecting site were pooled, $F_{S T}$ values averaged 0.078 (isoenzyme) and 0.062 (RAPD) for the 5 upper midwestern localities. Even infrapopulations representing different farms from a single geographic region showed moderate genetic differentiation, with isoenzyme and RAPD-based $F_{S T}$ estimates of 0.080 and 0.093 , respectively. Ascaris suum populations appear to be characterized by much more subdivision than described for $O$. ostertagi by Blouin et al. (1992), even though both nematodes are parasites of livestock and are subjected to frequent transport. However, one potentially important difference between these species is that although susceptible cattle may each host 10,000-100,000 O. ostertagi (Armour et al., 1979; Williams et al., 1983), pigs infected with $A$. suum harbor much smaller infrapopulations. This difference in the size of breeding populations may cause genetic drift within geographic localities of $A$. suum, effectively promoting independent differentiation of populations.

Potential complicating effects of parasite genetic structure such as asexual amplification within intermediate hosts (digeneans), overdispersion, and considerations of geographical scale have rarely been investigated. One exception involves the studies of Lydeard et al. (1989) and Mulvey et al. (1991) on the genetic structure of liver flukes (Fascioloides magna) parasitizing whitetailed deer. Populations of $F$. magna representing Savannah River Site hunt units showed low average differentiation $\left(F_{S T}\right.$ $=0.016$ ), and patterns of genetic distance between populations of flukes were not related to patterns of host differentiation or to the geographic distance between hunt units. In contrast, populations of $F$. magna collected from different states (South Carolina and Tennessee) showed markedly greater levels of differentiation (mean $F_{S T}=0.176$ ) and an isolation-by-distance effect (Mulvey et al., 1991). As is characteristic of many host-parasite systems, the distribution of $F$. magna among deer hosts was highly aggregated, and this appeared to influence the genetic structure of fluke populations. Asexual reproduction of $F$. mag$n a$ in snail intermediate hosts results in localized distributions of metacercariae of the same clone, and this clumping of identical metacercarie increases the likelihood that deer will be infected with adults representing 1 clone. In their study, Mulvey et al. (1991) found that deer tend to be infected with flukes of the same multilocus genotype, and simulation studies suggested that approximately one-half of the mean $F_{S T}$ values may be explained by this nonrandom distribution of fluke genotypes among deer hosts.

\section{FINAL COMMENTS}

The development of PCR-based DNA markers has provided new opportunities for assessing the genotypes of small individual parasites and investigating population genetic structure. Published studies employing traditional biochemical genetic markers on relatively large individual parasites have revealed marked differences in population genetic structure among certain taxa, and some of these differences may be attributed to parasite or host factors that influence the geographic movement of individuals or dissemination of life cycle stages in the environment. Designing testable hypotheses to assess the relationships between life history variables of parasites and patterns of genetic structure is likely to be challenging. Due to the potentially confounding effects caused by host parameters, studies of genetic structure in parasites may benefit from a comparative approach in which several species of parasites that co-occur in populations of a single host species are investigated simultaneously. Investigating the genetic structure of the host populations may also prove beneficial, although few host-parasite systems are likely to be characterized by absolute linkage between host and parasite gene flow. Finally, a phylogenetic perspective may offer the greatest opportunity for investigating the contri- 
butions of different parasite life history features to the genetic structure of their populations. For example, sister-taxa of parasites that coexist in the same host species and differ in one or few life history features would appear to represent the ideal case for assessing the influence of parasite attributes on population genetic structure.

\section{ACKNOWLEDGMENTS}

I thank two anonymous reviewers for insightful comments on the manuscript. I am also grateful to A. Nadler for her patience during preparation of the manuscript, and to G. W. Esch for his tolerance of my noncompliance with proposed deadlines. This study was supported, in part by grants from the NIH (AI34151-01) and NSF (DEB-9208024).

\section{LITERATURE CITED}

AdAmson, M. L. 1989. Evolutionary biology of the Oxyurida (Nematoda): Biofacies of a haplodiploid taxon. In Advances in parasitology, Vol. 28, J. R. Baker and R. Muller (eds.). Academic Press, London, U.K., p. 175-228.

Armour, J., K. Bairden, J. L. Duncan, F. W. Jennings, and J. J. PARKINS. 1979. Observations on ostertagiasis in young cattle over two grazing seasons with special reference to plasma pepsinogen levels. Veterinary Record 106: 500-503.

AviSE, J. C. 1994. Molecular markers, natural history and evolution. Chapman and Hall, New York, New York, $511 \mathrm{p}$.

- J. Arnold, R. M. Ball, E. Bermingham, T. Lamb, J. E. Neigel, C. A. REEB, AND N. C. SAUNDERS. 1987. Intraspecific phylogeography: The mitochondrial DNA bridge between population genetics and systematics. Annual Review of Ecology and Systematics 18: 489-522.

Barton, N. H., AND M. Slatkin. 1986. A quasi-equilibrium theory of the distribution of rare alleles in a subdivided population. Heredity 56: 409-415.

Blouin, M. S., J. B. Dame, C. A. Tarrant, and C. H. Courtney. 1992. Unusual population genetics of a parasitic nematode: $\mathrm{mtDNA}$ variation within and among populations. Evolution 46: 470-476.

Brudastov, A. N., V. R. Lemelev, S. K. Kholnukhanedov, and L. N. KRASNOS. 1971. The clinical picture of the migration phase of ascariasis in self-infection. Meditsinskaya Parazitologiya i Parazitarnye Bolezni 40: 165-168.

Bullini, L., G. Nascetti, L. Paggi, P. Orecchia, S. Mattiucci, and B. BERLAND. 1986. Genetic variation of ascaridoid worms with different life cycles. Evolution 40: 437-440.

Chesser, R. K., O. E. Rhodes Jr., D. W. Sugg, and A. Schnabel. 1993. Effective sizes for subdivided populations. Genetics 135: 1221-1232.

Crow, J. F., AND K. AOKI. 1984. Group selection for a polygenic behavioral trait: Estimating the degree of population subdivision. Proceedings of the National Academy of Sciences USA 81: 60736077.

- AND M. KIMURA. 1970. An introduction to population genetics theory, 1st ed. Harper and Row, New York, New York, 591 p.

Dame, J. B., M. S. Blouin, AND C. H. Courtney. 1993. Genetic structure of populations of Ostertagia ostertagi. Veterinary Parasitology 46: 55-62.

DARWIN, C. 1859 . On the origin of species by means of natural selection, or the preservation of favoured races in the struggle for life. Reprinted. E. A. Weeks and Company, Chicago, Illinois, 503 p.

ENDLER, J. A. 1986. Natural selection in the wild. Princeton University Press, Princeton, New Jersey, 336 p.

ESCH, G. W., AND J. C. FERnÁNDEZ. 1993. A functional biology of parasitism. Chapman and Hall, London, U.K., 337 p.

FALCONER, D. S. 1981. Introduction to quantitative genetics, 2nd ed. Longman, New York, New York, 340 p.

Felsenstein, J. 1982. How can we infer geography and history from gene frequencies? Journal of Theoretical Biology 96: 9-20.
FiSHER, R. A. 1930. The genetical theory of natural selection. Oxford University Press, Oxford, U.K., 272 p.

FoRD, E. B. 1964. Ecological genetics. Methuen and Company, London, U.K., 335 p.

Frank, G. R., R. P. Herd, K. S. Marbury, and J. C. Williams. 1986. Effects of transfer of Ostertagia ostertagi between northern and southern U.S.A. on the pattern and frequency of hypobiosis. International Journal for Parasitology 16: 391-398.

AND E. R. WILLIS. 1988. Additional investigations on hypobiosis of Ostertagia ostertagi after transfer between northern and southern U.S.A. International Journal for Parasitology 18: 171-177.

GrANT, W. N. 1994. Genetic variation in parasitic nematodes and its implications. International Journal for Parasitology 24: 821-830.

GYLLENSTEN, U. B. 1985. The genetic structure of fish: Differences in the intraspecific distribution of biochemical genetic variation between marine, anadromous, and freshwater species. Journal of Fish Biology 26: 691-699.

Hafner, J. C., D. J. Hafner, J. L. Patton, ANd M. F. Smith. 1983 Contact zones and the genetics of differentiation in the pocket gopher Thomomys bottae (Rodentia: Geomyidae). Systematic Zoology 32: $1-20$.

HALDANE, J. B. S. 1930. A mathematical theory of natural and artificial selection. Part 4. Isolation. Proceedings of the Cambridge Philosophical Society 26: 220-230.

HANDEL, S. N. 1982. Dynamics of gene flow in an experimental population of Cucumis melo (Cucurbitaceae). American Journal of Botany 69: $1538-1546$.

HeDrICK, P. W. 1983. Genetics of populations. Science Books International, Boston, Massachusetts, $629 \mathrm{p}$.

HilbuRN, L. R., AND P. W. SATtLer. 1986a. Electrophoretically detectable protein variation in natural populations of the lone star tick, Amblyomma americanum (Acari: Ixodidae). Heredity 56: 6774.

- AND - 1986b. Are tick populations really less variable and should they be? Heredity 57: 113-117.

Hillis, D. M., AND C. MoRITZ. 1990. Molecular systematics. Sinauer Associates, Sunderland, Massachusetts, 588 p.

Hudson, R. R. 1990 . Gene genealogies and the coalescent process. In Oxford surveys in evolutionary biology, Vol. 7, D. J. Futuyma and J. Antonovics (eds.). Oxford University Press, Oxford, U.K., p. 144.

-, M. Slatkin, AND W. P. Maddison. 1992. Estimation of levels of gene flow from DNA sequence data using cladistic and pairwise methods. Genetics 132: 583-589.

KENNEDY, C. R. 1987. Long term stability in the population levels of the eye fluke Tylodelphys podicipina (Digenea: Diplostomatidae) in perch. Journal of Fish Biology 31: 571-581.

, AND R. J. Burrough. 1977. The population biology of two species of eye fluke, Diplostomum gasterostei and Tylodelphys clavata, in perch. Journal of Fish Biology 11: 619-633.

KIMURA, M. 1962. On the probability of fixation of mutant genes in a population. Genetics 47: 713-719.

1983. The neutral theory of molecular evolution. Cambridge University Press, Cambridge, U.K., 367 p.

, AND J. F. CROw. 1963. The measurement of effective population number. Evolution 17: 279-288.

, AND T. OHTA. 1969. The average number of generations until fixation of a mutant gene in a finite population. Genetics 61: 763771.

Lydeard, C., M. Mulvey, J. M. Aho, and P. K. Kennedy. 1989. Genetic variability among natural populations of the liver fluke, Fascioloides magna, in white-tailed deer, Odocoileus virginianus. Canadian Journal of Zoology 67: 2021-2025.

LYMBERY, A. J., AND R. C. A. THOMPSON. 1988. Electrophoretic analysis of genetic variation in Echinococcus granulosus from domestic hosts in Australia. International Journal for Parasitology 18: 803811.

Margolis, L., G. W. Esch, J. C. Holmes, A. M. Kuris, and G. A. SCHAD. 1982. The use of ecological terms in parasitology (Report of an ad hoc committee of the American Society of Parasitologists). Journal of Parasitology 68: 131-133. 
Maruyama, T., AND M. KimUra. 1974. Geographical uniformity of selectively neutral polymorphisms. Nature (London) 249: 30-32.

$\longrightarrow$, AND 1980 . Genetic variability and effective population size when local extinction and recolonization of subpopulations are frequent. Proceedings of the National Academy of Sciences USA 77: 6710-6714.

MAY, R. M. 1973. Stability and complexity in model ecosystems. Princeton University Press, Princeton, New Jersey, 235 p.

MAYR, E. 1954. Change of genetic environment and evolution. In Evolution as a process, J. Huxley, A. C. Hardy, and E. B. Ford (eds.). Allen and Unwin, London, U.K., p. 157-180.

MCMANUS, D. P. 1985. Enzyme analysis of natural populations of Schistocephalus solidus and Ligula intestinalis. Journal of Helminthology 59: 323-332.

Mulvey, M., J. M. Aho, C. LydeArd, P. L. Leberg, ANd M. H. Smith. 1991. Comparative population genetic structure of a parasite (Fascioloides magna) and its definitive host. Evolution 45: 1628-1640.

NADLER, S. A. 1990. Molecular approaches to studying helminth population genetics and phylogeny. International Journal for Parasitology 20: 11-29.

- M. S. HAFNer, J. C. HAFNeR, AND D. J. HAFNer. 1990. Genetic differentiation among chewing louse populations (Mallophaga: Trichodectidae) in a pocket gopher contact zone (Rodentia: Geomyidae). Evolution 44: 942-951.

- R. L. LindQuist, AND T. J. NeAR. 1995. Genetic structure of midwestern Ascaris suum populations: A comparison of isoenzyme and RAPD markers. Journal of Parasitology 80: (in press).

NAGYLAKI, T. 1975. Conditions for the existence of clines. Genetics 80: $595-615$.

Nascetti, G., R. Cianchi, S. Mattiucci, S. D’Amelio, P. Orecchia, L. Paggi, J. Brattey, B. Berland, J. W. Smith, and L. Bullini. 1993. Three sibling species within Contracaecum osculatum (Nematoda, Ascaridida, Ascaridoidea) from the atlantic arctic-boreal region: Reproductive isolation and host preferences. International Journal for Parasitology 23: 105-120.

Nei, M., and A. Chakravarti. 1977. Drift variances of $F_{S T}$ and $G_{S T}$ statistics obtained from a finite number of isolated populations. Theoretical Population Biology 11: 307-325.

Paggi, L., G. Nascetti, R. Cianchi, P. Orecchia, S. Mattiucci, S. D'Amelio, B. Berland, J. Brattey, J. W. Smith, and L. Bullini. 1991. Genetic evidence for three species within Pseudoterranova decipiens (Nematoda, Ascaridida, Ascaridoidea) in the north Atlantic and Norwegian and Barents seas. International Journal for Parasitology 21: 195-212.

PrICE, P. W. 1980. Evolutionary biology of parasites. Princeton University Press, Princeton, New Jersey, 237 p.

Schad, G. A., AND R. M. Anderson. 1985. Predisposition to hookworm infection in humans. Science 228: 1537-1539.

SHIELDS, W. M. 1993. The natural and unnatural history of inbreeding and outbreeding. In The natural history of inbreeding and outbreeding, N. W. Thornhill (ed.). University of Chicago Press, Chicago, Illinois, p. 143-169.

SLATKIN, M. 1985. Rare alleles as indicators of gene flow. Evolution 39: $53-65$.
1987. Gene flow and the geographic structure of natural populations. Science 236: 787-792.

- 1991. Inbreeding coefficients and coalescence times. Genetical Research 58: 167-175.

. 1993. Isolation by distance in equilibrium and nonequilibrium populations. Evolution 47: 264-279.

, AND N. H. BARTON. 1989. A comparison of three indirect methods for estimating average levels of gene flow. Evolution 43: 1349-1368.

, AND W. P. MADDISON. 1989. A cladistic measure of gene flow from the phylogenies of alleles. Genetics 123: 603-613.

Smeal, M. G., AND A. D. Donald. 1981. Effects of inhibition of development on the transfer of Ostertagia ostertagi between geographical regions of Australia. Parasitology 82: 389-399.

TAKaHATA, N. 1983. Gene identity and genetic differentiation of populations in the finite island model. Genetics 104: 497-512.

Van Den Bussche, R. A., M. J. Hamilton, ANd R. K. Chesser. 1986. Problems of estimating gene diversity among populations. Texas Journal of Science 38: 281-287.

Ward, R. D., D. O. F. Skibinski, AND M. Woodwark. 1992. Protein heterozygosity, protein structure, and taxonomic differentiation. Evolutionary Biology 26: 73-159.

WeIR, B. S. 1990. Genetic data analysis. Sinauer Associates, Sunderland, Massachusetts, $377 \mathrm{p}$.

- AND C. C. COCKerham. 1984. Estimating $F$-statistics for the analysis of population structure. Evolution 38: 1358-1370.

Williams, J. C., J. W. Knox, B. A. Baumann, T. G. Snider, M. G. Kimball, AND T. J. Hoerner. 1983. Seasonal changes of gastrointestinal nematode populations in yearling beef cattle in Louisiana with emphasis on prevalence of inhibition in Ostertagia ostertagi. International Journal of Parasitology 13: 133-143.

Wright, S. 1912. Notes on the anatomy of the trematode, Microphallus opacus. Transactions of the American Microscopical Society 31: 167-175.

. 1922. Coefficients of inbreeding and relationship. American Naturalist 56: 330-338.

1931. Evolution in Mendelian populations. Genetics 16: 97 159.

. 1932. The roles of mutation, inbreeding, crossbreeding and selection in evolution. Proceedings of the Sixth International Congress of Genetics 1: 356-366.

- 1938. Size of population and breeding structure in relation to evolution. Science 87: 430-431.

. 1940. Breeding structure of populations in relation to speciation. American Naturalist 74: 232-248.

- 1951. The genetical structure of populations. Annals of Eugenics 15: 323-354.

. 1956. Modes of selection. American Naturalist 90: 5-24.

. 1965. The interpretation of population structure by $F$-statistics with special regard to systems of mating. Evolution 19: 395-420.

. 1978. Evolution and the genetics of populations, Vol. 4, Variability within and among natural populations. University of Chicago Press, Chicago, Illinois, 580 p.

- 1982. The shifting balance theory and macroevolution. Annual Review of Genetics 16: 1-19. 